\title{
Paleofire records reveal possible mechanisms of the termination of the Late Devonian Upper Kellwasser marine anoxia
}

\author{
MAN LU ${ }^{1}$, YUEHAN LU1, YONGGE SUN ${ }^{2}$, \\ RICHARD CARROLL $^{3}$, TAKEHITO IKEJIRI ${ }^{1}$ \\ ${ }^{1}$ Molecular Eco-Geochemistry Laboratory, Department of \\ Geological Sciences, University of Alabama, Tuscaloosa, \\ AL 35485, USA \\ ${ }^{2}$ Environmental and Biogeochemical Institute, Zhejiang \\ University, Hangzhou Zhejiang 310027, China \\ ${ }^{3}$ Energy Investigation Program, Geological Survey of \\ Alabama, Tuscaloosa, AL 35401, USA
}

The Upper Kellwasser Event (UKW) during the Late Frasnian is characterized by worldwide depositions of organic-rich strata due to marine anoxia, yet the causal mechanism of termination of anoxic events has not been unambiguously identified. In this study, we test the hypothesis that rising atmospheric oxygen led to the termination of UKW anoxia. We used paleo-wildfire as an indicator of $\mathrm{pO}_{2}$ and reconstructed changes in paleo-wildfire across the UKW interval via analyzing fossil charcoals and pyrogenic polycyclic aromatic hydrocarbons (PAHs) from the Upper Devonian Chattanooga Shale in the southern Appalachian Basin. We found fossil charcoals and pyrogenic PAHs were low during the Late Frasnian but increased dramatically during the Famennian, suggesting a rapid rise in $\mathrm{pO}_{2}$ following the UKW. Concurrently, photic zone euxinia, as indicated by aryl isoprenoids derived from Chlorobi, reached the maximum during the UKW and declined during the Famennian. Marine primary productivity, as indicated by algae-derived biomarkers and plankton cysts, and terrestrial inputs, as indicated by vascular plant biomarkers and weathering indices, followed the same trend, i.e., showing elevated values during UKW and decreases rapidly during the Famennian. Our data suggest that rising $\mathrm{pO}_{2}$ and decreased nutrient inputs to coastal oceans during the early Famennian may collectively lead to the UKW marine anoxia termination. 